\title{
The Influence of Harmonics on Error Stability of Energy Meter Verification Device and Its Suppression Measures
}

\author{
Lei Song ${ }^{1}$, Huan-jun $\mathrm{Chen}^{1}$, Yi-na Chen ${ }^{1}$, Yong-jin Xu ${ }^{1}$, Yong-jia Zhou ${ }^{1}$, Chenhui Zhou ${ }^{1}$ \\ Ran $\mathrm{Lu}^{1}$,Hai-feng Wang ${ }^{3}$, Li-xin Wang ${ }^{1}$, Xiao-qiong Huang ${ }^{1}$ \\ ${ }^{1}$ Electric Power Research Institute of State Grid Zhejiang Province Electric Power Company, Hangzhou, 310014, China. \\ 2 State Grid Hangzhou Power Supply Company \\ 332794975@qq.com,xvyongj@126.com,yj_z@sina.com,xqmyself@qq.com
}

\begin{abstract}
In view of the problem of poor error stability of the three-phase energy meter verification device under low current load, the working principle and error calculation method of the device are analyzed. The harmonics content and error data of the device under low current load before and after the installation of the isolation transformer are tested on site. And the role of the isolation transformer in suppressing the harmonics of the device is analyzed. From the harmonics content and error data of the output current of the device before and after the installation of the isolation transformer, it can be seen that the isolation transformer can effectively suppress the harmonics content of the device at the time of low current output and also improve the error stability under low current load.
\end{abstract}

\section{INTRODUCTION}

Electric energy is the main source of energy for the national economy and people's lives, and plays a decisive role in the development of the country. The electric energy measurement data involves the economic benefits of power generation, power supply and power consumption, and is also an important basis for the calculation of many technical indicators. The energy meter is used as a measuring meter for the settlement of trade between power supply enterprises, power generation enterprises and power customers, and is a national energy metering device for compulsory verification ${ }^{[1-2]}$. The energy meter verification device is parameterized according to the national verification regulations. ${ }^{[3-4]}$

The three-phase energy meter verification device with the accuracy class of 0.05 is mainly used to check the three-phase energy meter with the accuracy class such as $0.2 \mathrm{~S}$ and $0.5 \mathrm{~S}$ connected by the transformer, and the error point of the minimum current should be measured to 3 $\mathrm{mA}$. When testing the device, it is found that the error of the device at the $3 \mathrm{~mA}, 6 \mathrm{~mA}$ and $15 \mathrm{~mA}$ load points fluctuate greatly. The test standard deviation and power stability do not meet the requirements of JJG597-2005 $A C$ Energy Meter Verification Device ${ }^{[5]}$. In this paper, it is found that the higher harmonics content of the device is the reason why the error fluctuates greatly under low current load. Theoretical analysis and experimental tests have proved that the installation of the isolation transformer can effectively suppress harmonics of the device and improve power stability, thereby reducing error fluctuation.

\section{WORKING PRINCIPLE AND TECHNICAL PARAMETERS OF THREE- PHASE ENERGY METER VERIFICATION DEVICE}

\section{A. Working principle of three-phase energy meter verification device}

The three-phase energy meter verification device is mainly composed of a signal source, a power source, a current, a voltage output conversion circuit, a working power supply circuit, a multi-function standard energy meter and a distributed error processor. The voltage and current signals generated by the signal source are respectively sent to the voltage power amplifier and the current power amplifier for power amplification through respective feedback compensation adjustment circuits. The voltage signal is boosted by the voltage booster and sent to the calibrated energy meter and the standard energy meter. After the current signal is boosted by the current booster, it is output from the current output terminal of the device. And it is connected to each of the calibrated energy meter and the standard energy meter current coil to return to the current booster. The energy meter error and various detections are calculated by the error processor. Determine the voltage, current and meter parameters to be output through the human-machine interface part (i.e. the keyboard part) on the computer or 
signal source, and send the waveform command that needs to be output to the DSP processing chip. The DSP chip is used to transmit data to the DA conversion chip in real time at high speed, and various waveforms required for synthesis are generated ${ }^{[6]}$.

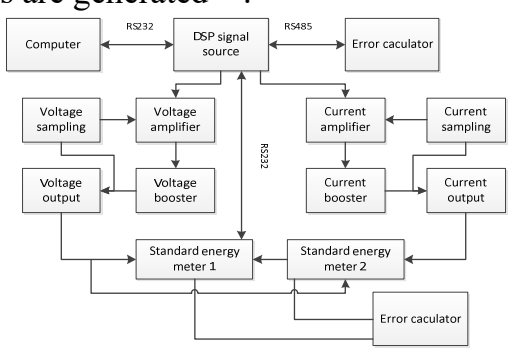

Fig.1 PRINCIPLE OF THREE-PHASE ENERGY METER VERIFICATION DEVICE

\section{$B$. Principle of error calculation for three- phase energy meter verification device}

The three-phase energy meter verification device with the accuracy class of 0.05 uses the error calculation principle of the digital multiplier, and calculates the power by sampling the instantaneous voltage and current values of the circuit under test ${ }^{[7-8]}$. The AC voltage and current of the circuit under test can be expressed asT:

$$
\begin{aligned}
& u(t)=U_{m} \sin \omega t \\
& i(t)=I_{m} \sin (\omega t-\varphi)
\end{aligned}
$$

The voltage and current are simultaneously sampled at time intervals of $\Delta \mathrm{t}$, and with $\mathrm{T}=\mathrm{N} \Delta \mathrm{t}$, the average power $\mathrm{P}$ can be expressed as:

$$
P=\sum_{k=1}^{n} u\left(t_{k}\right) \cdot i\left(t_{k}\right)
$$

As $\Delta t=t_{k}-t_{k-1}$, so the energy in one cycle is:

$$
W=\sum_{k=1}^{n} u\left(t_{k}\right) \cdot i\left(t_{k}\right) \Delta t
$$

Where, $\mathrm{U}_{\mathrm{m}}$ and $\mathrm{I}_{\mathrm{m}}$ represent the voltage and current peak; $\varphi$ represents the phase difference between voltage and current.

\section{Technical parameters of three-phase energy meter verification device}

Model: PTC-8320M

A

Measurement range: $3 \times(57.7 \sim 380) \mathrm{V}, 3 \times(0.01 \sim 10)$

Accuracy class: 0.05

\section{ANALYSIS OF THE INFLUENCE OF HARMONICS ON ERROR STABILITY OF THREE-PHASE ENERGY METER VERIFICATION DEVICE UNDER LOW CURRENT LOAD}

Since the harmonics occupy a large proportion under low current load of the device, the influence of harmonics on the power stability and error stability of the device under low current load is more obvious. The harmonics content and error data were measured for the three-phase energy meter verification device with the accuracy class of 0.05 . For the accuracy of the test data, the tests were performed under different load currents before the installation of the isolation transformer.

\section{A. The harmonics content and error test of three-phase energy meter verification device under low current load}

The micro-current meter is used to sample the output current of the A phase of the three-phase energy meter verification device's power supply without the isolation transformer, and the sampling signal is transmitted to the electric energy recording analyzer. The electric energy recording analyzer calculates and displays the harmonics of the sampling current. The three-phase energy meter verification device tester is used to verify the error data of the device. Figure 2 is the test circuit for verifying the harmonics of the device. Table 1 and Table 2 respectively show the measured harmonics content of the verification device under two different low current loads. Table 3 and Table 4 respectively show the error data of the verification device under the corresponding two kinds of loads.

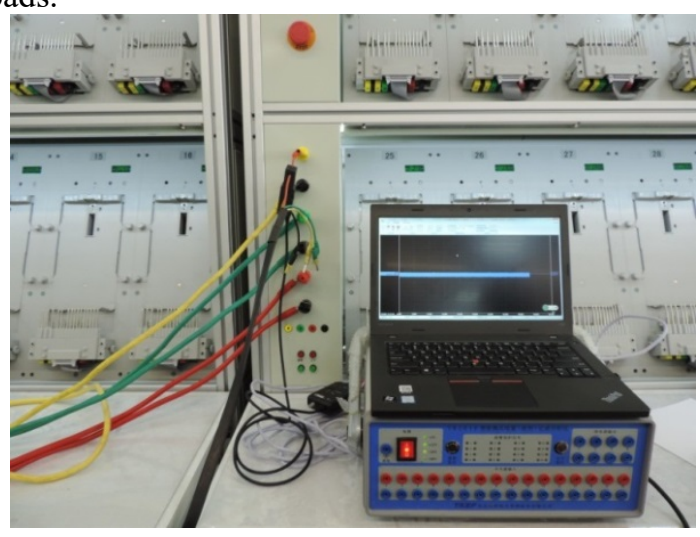

FIG.2 HARMONICS TEST CIRCUIT OF VERIFICATION DEVICE

TAB. 1 HARMONICS CONTENTS OF VERIFICATION $\operatorname{DEVICE}(\mathrm{U}=3 \times 220 / 380 \mathrm{~V}, \mathrm{I}=3 \mathrm{~mA}, \operatorname{Cos} \varphi=1.0)$

\begin{tabular}{ccccc}
\hline Harmonics frequency & 3 times & 5 times & 7 times & 9 times \\
\hline Harmonics content & 35.065 & 23.834 & 15.684 & 20.202 \\
\hline Harmonics frequency & 11 times & 13 times & 15 times & 17 times \\
\hline Harmonics content & 11.872 & 10.301 & 27.990 & 22.885 \\
\hline
\end{tabular}

TAB. 2 HARMONICS CONTENTS OF VERIFICATION DEVICE $(\mathrm{U}=3 \times 220 / 380 \mathrm{~V}, \mathrm{I}=3 \mathrm{MA}, \cos \Phi=0.5 \mathrm{~L})$

\begin{tabular}{ccccc}
\hline Harmonics frequency & 3 times & 5 times & 7 times & 9 times \\
\hline $\begin{array}{c}\text { Harmonics content } \\
(\%)\end{array}$ & 39.772 & 14.341 & 5.302 & 15.379 \\
\hline Harmonics frequency & 11 times & 13 times & 15 times & 17 times \\
\hline $\begin{array}{c}\text { Harmonics content } \\
(\%)\end{array}$ & 10.039 & 11.820 & 7.814 & 19.154 \\
\hline
\end{tabular}


TAB.3 MEASUREMENT ERROR DATA OF VERIFICATION DEVICE $(\mathrm{U}=3 \times 220 / 380 \mathrm{~V}, \mathrm{I}=3 \mathrm{MA}, \operatorname{Cos} \Phi=1.0)$

\begin{tabular}{ccccc}
\hline $\begin{array}{c}\text { Number of } \\
\text { measurements }\end{array}$ & 1 & 2 & 3 & 4 \\
\hline Error (\%) & 0.0100 & -0.0094 & 0.0045 & 0.0050 \\
\hline $\begin{array}{c}\text { Number of } \\
\text { measurements }\end{array}$ & 5 & 6 & 7 & 8 \\
\hline Error (\%) & -0.0064 & 0.0155 & 0.0045 & -0.0079 \\
\hline $\begin{array}{c}\text { Number of } \\
\text { measurements }\end{array}$ & 9 & 10 & standard & 0.009 \\
\cline { 1 - 3 } Error (\%) & -0.0019 & 0.0130 & deviation & $\bullet$ \\
\hline
\end{tabular}

TAB.4 MEASUREMENT ERROR DATA OF VERIFICATION DEVICE $(\mathrm{U}=3 \times 220 / 380 \mathrm{~V}, \mathrm{I}=3 \mathrm{MA}, \operatorname{COS} \Phi=0.5 \mathrm{~L})$

\begin{tabular}{|c|c|c|c|c|}
\hline Number of measurements & 1 & 2 & 3 & 4 \\
\hline Error $(\%)$ & 0.0100 & -0.0009 & 0.0035 & -0.0009 \\
\hline Number of measurements & 5 & 6 & 7 & 8 \\
\hline Error $(\%)$ & 0.0015 & 0.0160 & -0.0044 & 0.0035 \\
\hline Number of measurements & 9 & 10 & \multirow{2}{*}{$\begin{array}{l}\text { standard } \\
\text { deviation }\end{array}$} & \multirow{2}{*}{0.007} \\
\hline Error $(\%)$ & 0.0125 & 0.0110 & & \\
\hline
\end{tabular}

It can be seen from the test results that when the three-phase energy meter verification device under low current load, the odd-order harmonics of the A phase output current is higher, resulting in poor error stability of the device under low current load. The standard deviation of the error at $3 \mathrm{~mA}$ exceeds the value specified in the JJG597-2005 AC Energy Meter Verification Device Verification Regulations. Therefore, the harmonics of the power supply must be suppressed to reduce the influence of harmonics on the stability of the device error.

\section{IV.THE EFFECT OF ISOLATION TRANSFORMER ON SUPPRESSING POWER SUPPLY HARMONICS AND MATHEMATICAL MODEL ANALYSIS}

\section{A. The role of isolation transformer}

The main function of the isolation transformer is to completely insulate the electrical side of the primary side and the secondary side, to isolate the current waveform distortion caused by the nonlinear load, and to use the high frequency loss of the iron core to suppress the high frequency harmonics from being transmitted to the secondary circuit ${ }^{[9]}$.

\section{$B$. The equivalent circuit of the isolation transformer}

The equivalent circuit of the isolation transformer mainly composes of magnetic reluctance, iron loss, copper loss, leakage flux and distributed capacitance. Since the voltage of the power supply does not change much, the parameters of the transformer can be approximated as follows, and the equivalent circuit is shown in Figure $3^{[10]}$.

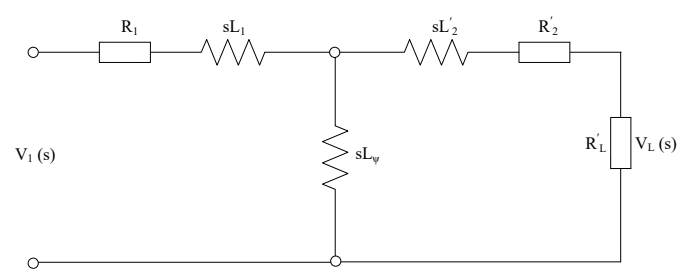

FIg.3 THE EQUIVALENT CIRCUIT OF ISOLATION TRANSFORMER

According to the equivalent circuit of the isolation transformer, the transfer function is:

$$
\frac{V_{L}(s)}{V_{1}(s)}=\frac{R_{L}^{\prime} L_{\psi} s}{A s^{2}+B s+C}
$$

Where,

$$
\begin{aligned}
A & =L_{1} L_{2}^{\prime}+L_{2}^{\prime} L_{\Psi}+L_{1} L_{\Psi} \\
B & =R_{1} L_{2}^{\prime}+R_{1} L_{\Psi}+R_{2}^{\prime} L_{1} \\
& +R_{L}^{\prime} L_{1}+R_{2}^{\prime} L_{\Psi}+R_{L}^{\prime} L_{\Psi} \\
C & =R_{1} R_{2}^{\prime}+R_{1} R_{L}^{\prime}
\end{aligned}
$$

In the formula, $\mathrm{V}_{1}(\mathrm{~s})$ and $\mathrm{V}_{\mathrm{L}}(\mathrm{s})$ are the Laplace transforms of the input and output voltages of the transformer respectively; $\mathrm{R}_{1}$ and $\mathrm{L}_{1}$ are the resistance and leakage inductance of the primary side of the transformer respectively; $\mathrm{L}_{\Psi}$ is the inductance of the transformer; $\mathrm{R}_{2}$ and $L_{2}{ }_{2}$ are the value of the resistance and leakage inductance of the secondary coil to the primary side; $\mathrm{R}_{\mathrm{L}}$ is the equivalent load.

It can be seen from equation (5) that the isolation transformer is a band pass filter that can effectively filter out higher harmonics.

\section{Harmonics and error test of low current load after installation of isolation transformer for three-phase energy meter verification device}

Using the same test method, the harmonics content and error data of the device after the isolation transformer installed were tested. The test results are shown in Table 5 to Table 8 .

TAB.5 HARMONICS CONTENTS OF VERIFICATION DEVICE $(\mathrm{U}=3 \times 220 / 380 \mathrm{~V}, \mathrm{I}=3 \mathrm{MA}, \operatorname{COS} \Phi=1.0)$

\begin{tabular}{ccccc}
\hline Harmonics frequency & 3 times & 5 times & 7 times & 9 times \\
\hline $\begin{array}{c}\text { Harmonics content } \\
(\%)\end{array}$ & 0.6597 & 0.5260 & 0.6910 & 4.3923 \\
\hline Harmonics frequency & 11 times & 13 times & 15 times & 17 times \\
\hline $\begin{array}{c}\text { Harmonics content } \\
(\%)\end{array}$ & 0.7461 & 0.2599 & 0.7166 & 0.5274 \\
\hline
\end{tabular}

TAB.6 HARMONICS CONTENTS OF VERIFICATION DEVICE $(\mathrm{U}=3 \times 220 / 380 \mathrm{~V}, \mathrm{I}=3 \mathrm{MA}, \mathrm{COS} \Phi=0.5 \mathrm{~L})$

\begin{tabular}{ccccc}
\hline Harmonics frequency & 3 times & 5 times & 7 times & 9 times \\
\hline $\begin{array}{c}\text { Harmonics content } \\
(\%)\end{array}$ & 1.3939 & 0.3630 & 1.2658 & 2.4094 \\
\hline Harmonics frequency & 11 times & 13 times & 15 times & 17 times \\
\hline
\end{tabular}




\begin{tabular}{ccccc}
\hline $\begin{array}{c}\text { Harmonics content } \\
(\%)\end{array}$ & 0.9581 & 0.9437 & 1.3489 & 1.2350 \\
\hline
\end{tabular}

TAB.7 MEASUREMENT ERROR DATA OF VERIFICATION DEVICE $(\mathrm{U}=3 \times 220 / 380 \mathrm{~V}, \mathrm{I}=3 \mathrm{MA}, \operatorname{Cos} \Phi=1.0)$

\begin{tabular}{ccccc}
\hline Number of measurements & 1 & 2 & 3 & 4 \\
\hline Error (\%) & 0.0065 & 0.0045 & 0.0055 & 0.0060 \\
\hline Number of measurements & 5 & 6 & 7 & 8 \\
\hline Error (\%) & 0.0040 & 0.0015 & 0.0055 & 0.0060 \\
\hline Number of measurements & 9 & 10 & standard & \multirow{2}{*}{0.002} \\
\hline Error (\%) & 0.0055 & 0.0080 & deviation & \\
\hline
\end{tabular}

TAB. 8 MEASUREMENT ERROR DATA OF VERIFICATION DEVICE $(\mathrm{U}=3 \times 220 / 380 \mathrm{~V}, \mathrm{I}=3 \mathrm{MA}, \cos \Phi=0.5 \mathrm{~L})$

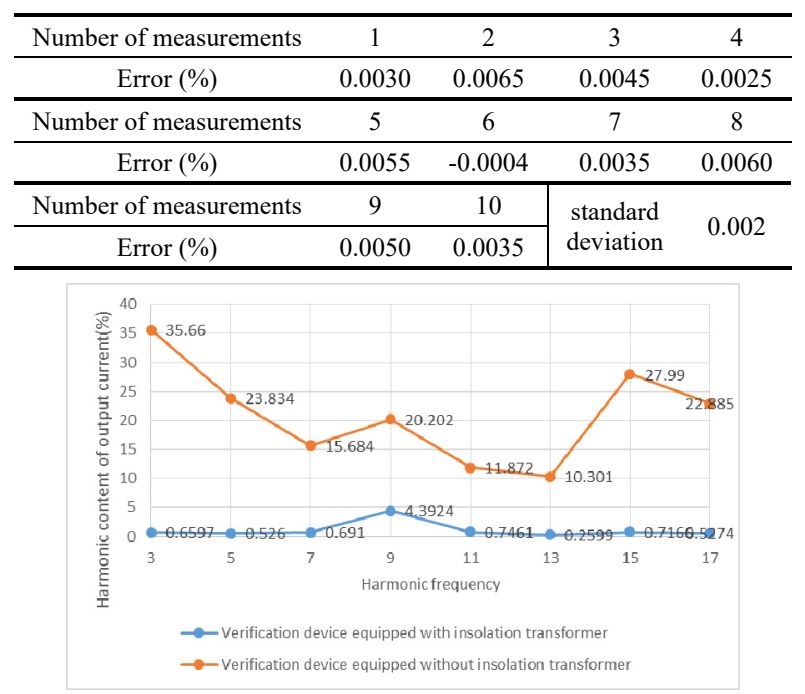

Fig.4 COMPARISON OF VERIFICATION DEVICE OUTPUT HARMONICSS BEFORE AND AFTER INSTALLING ISOLATION TRANSFORMER $(\mathrm{U}=3 \times 220 / 380 \mathrm{~V}, \mathrm{I}=3 \mathrm{MA}, \operatorname{COS} \Phi=1.0)$

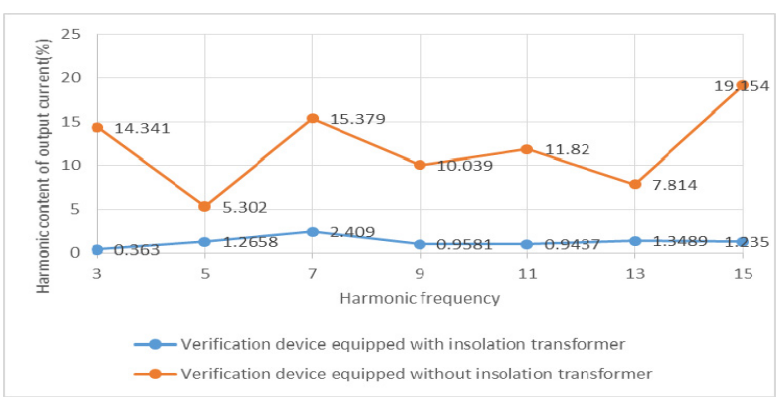

FIG.5 COMPARISON OF VERIFICATION DEVICE OUTPUT HARMONICSS BEFORE AND AFTER INSTALLING ISOLATION TRANSFORMER $(\mathrm{U}=3 \times 220 / 380 \mathrm{~V}, \mathrm{I}=3 \mathrm{MA}, \operatorname{COS} \Phi=0.5 \mathrm{~L})$

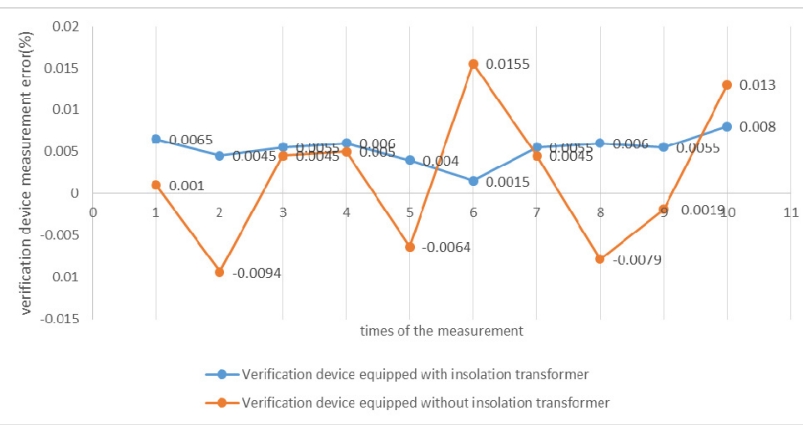

FIG.6 COMPARISON OF VERIFICATION DEVICE MEASUREMENT ERROR DATA BEFORE AND AFTER INSTALLING ISOLATION TRANSFORMER $(\mathrm{U}=3 \times 220 / 380 \mathrm{~V}, \mathrm{I}=3 \mathrm{MA}, \operatorname{COS} \Phi=1.0)$

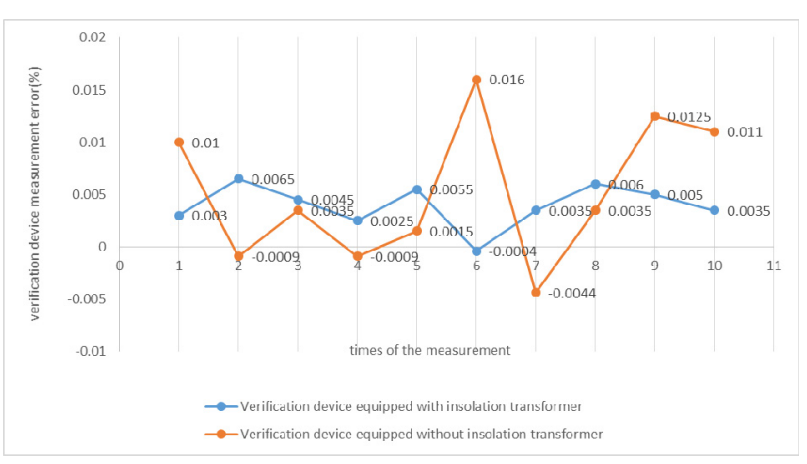

FIG.7 COMPARISON OF VERIFICATION DEVICE MEASUREMENT ERROR DATA BEFORE AND AFTER INSTALLING ISOLATION TRANSFORMER $(\mathrm{U}=3 \times 220 / 380 \mathrm{~V}, \mathrm{I}=3 \mathrm{MA}, \operatorname{COS} \Phi=0.5 \mathrm{~L})$

\section{COMPARISON AND ANALYSIS OF HARMONICS AND ERROR STABILITY OF THE THREE-PHASE ENERGY METER VERIFICATION DEVICE BEFORE AND AFTER INSTALLATION OF ISOLATION TRANSFORMER}

Figure 4 to Figure 7 show the harmonics contrast of the output current and the error comparison of the verification device before and after the installation of the isolation transformer. It can be seen from the comparison results that the isolation transformer has obvious inhibitory effect on the output harmonics of the device. After the installation of the isolation transformer, the error stability of the device under low current load has been significantly improved, and can meet the requirements of the JJG597-2005 AC energy meter verification device verification procedures.

\section{CONCLUSION}

The working principle, error calculation method and technical parameters of the three-phase energy meter verification device are introduced. The harmonics and error fluctuation data of the device under low current load are tested. It can be seen from the test data that the device has high harmonics content and poor error stability under low current load. The equivalent circuit is used to theoretically analyze the suppression effect of the isolation transformer on the harmonics of the device. The harmonics and error data of the device under low current load before and after the installation of the isolation transformer are tested. The comparison shows that the isolation transformer can effectively suppress the harmonics of the device and improve the error stability of the device under low current load. 


\section{REFERENCES}

1. Wang Rui, Yuan Jing, Qin Jian et al. Analysis and Experiment of Energy Metering Influence under Harmonics Condition of Electronic Energy Meter [J]. Electrical Measurement\&Instrumentation, 2015, 52(16A): 65-67.

2. Liu Ming-jie, Zhou Lin, Miao Chang-sheng et al. Study on the Development Discussion of New Generation Smart Meter [J]. Electrical Measurement\&Instrumentation, 2017, 54(18): 94-99.

3. Xu Zhuo, Chen Wei-qiang, Zhao Shan et al. Research and Application of On-site Automatic Verification System for Energy Meter Verification Device [J]. Electrical Measurement\&Instrumentation, 2015, 52(12): 60-63.

4. Wang Xin-ya, Li Xiang-rong, Zhao Jing-tao et al. The Research of Three-phase Standard Energy Meter with Class 0.01 and Type ST1000 [J]. Electrical Measurement \& Instrumentation, 2010, 47 (4): 62-66.

5. JJG597-2005, Verification Equipment for $\mathrm{AC}$ Energy Meters [S].
6. Huang Jin-juan, Wang Xiang. A Three-phase Energy Meter Verification Device for Synchronously Testing Active or Reactive Energy Error [J]. Zhejiang Electric Power, 2015, 8: 62-64.

7. Zhao Xian. The Effect of Voltage Flicker and Sag on Energy Metering [D]. Beijing: North China Electric Power University, 2008

8. Ye Rui-zhen, Features and Functions of Multifunction Energy Meter Verification Device [J]. Electrical Measurement \&Instrumentation, 2003, 40(450): 29-31.

9. Liu Qiang, Hu Cheng-qun. Requirements for Power Supply Quality of Computers in Power Grid Dispatching Automation System [J]. Electric Power Automation Equipment, 2008, 28(9): 119-121.

10. Wang Hong-rui, Li Jian-ping. 1:1 Isolation Transformer for Power Supply Filtering [J]. Journal of Northeast Institute of Heavy Mechinery1991, 15(2): 159-163. 